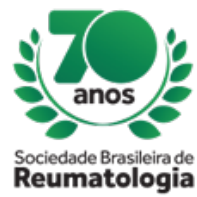

\title{
Crowned Dens Syndrome Secondary to Hyperparathyroidism
}

Mariana Lechitzki (HC-UFPR, Curitiba, PR, Brasil), Ana Luisa Woidello Miyazima (HC-UFPR, curitiba, PR, Brasil), Nathan Marostica Catolino (HC-UFPR, curitiba, PR, Brasil), André Luís de Souza Andretta (HCUFPR, curitiba, PR, Brasil), Isadora Welter Pioresan (HC-UFPR, curitiba, PR, Brasil), Luan Felipe Lückmann (HC-UFPR, curitiba, PR, Brasil), Keoma Azevedo Sabião (HC-UFPR, curitiba, PR, Brasil), Ana Beatriz Artigas Guimarães (HC-UFPR, curitiba, PR, Brasil), Eduardo Santos Paiva (HC-UFPR, curitiba, PR, Brasil)

\section{BACKGROUND}

Many rheumatologic abnormalities have been described in patients with classical symptomatic primary hyperparathyroidism, but none of these are commonly seen. They include the pseudogout, with pyrophosphate crystals into the joint and calcification of articular cartilage (chondrocalcinosis), most commonly affecting the wrists and knees.

The association between hyperparathyroidism and CPPD disease has been described in multiple case reports and is now established in epidemiologic studies.

The crowned dens syndrome (CDS) is a rare syndrome of crystal deposition, which is characterized by severe acute or recurrent axial neck pain, neck and shoulder girdle stiffness, associated fever and elevated inflammatory markers. The CDS can be identified by use of $\mathrm{CT}$, which is the preferred modality to demonstrate its presence. Findings may include CPP (or basic calcium phosphate) crystal masses at the atlanto-axial articulation and/or in the transverse ligament of the atlas and/or in the ligamentum flavum.

\section{CASE REPORT}

A 56 years-old woman, previously with high blood pressure, stroke in 2014, COPD, smoker, nephrolithiasis and osteoporosis, complained of diffuse bone pain, progressive weakness, fatigue and dyspnea in the last 2 years. She didn't have neck pain. On physical examination it was identified paraparesis, preserved sensitivity and normal reflexes. Admission laboratory examination: PTH: 973, Calcium: 13.6, Creatinine:1.4. In the investigation of paraparesis, the electroneuromyography was normal; the serology for syphilis was positive; spine CT scan, which did not identify compression of the medullar canal or nerve roots, revealed sclerotic bands in the upper and lower plateaus, alternated with central radiolucent aspect, assuming a column appearance in "rugger-jersey", related to the patient's underlying disease (primary hyperparathyroidism) and calcification of the yellow ligaments in the lower thoracic segment and practically the entire lumbar spine, and the periodontal ligaments, especially the transverse ligament of the atlas ("crowned dens" aspect), that may be related to the deposition of calcium pyrophosphate crystals.

The patient was submitted to parathyroidectomy, with confirmed parathyroid adenoma. Patient refused to continue the investigation of her suppose neurological deficit.

\section{CONCLUSION}

Although the diagnosis in this patient was an incidental finding on routine imaging examination, the crowned dens syndrome is a rare condition that should be remembered as a differential diagnosis of axial neck pain and promptly recognized, since it is a NSAID-responsive pathology with effective pain control and consequently improvement of the quality of life. Remembering hyperparathyroidism as a possible etiology of CPPD can help to elucidate the etiology of arthralgias in patients with this condition. 